\title{
SUFRIMIENTO, VERDAD Y JUSTICIA
}

\author{
Juan Carlos Aguirre García*
}

\section{INTRODUCCIÓN}

La historia sólo narra la gesta de los "vencedores" y la humillación del vencido. En sus datos se analizan las causas y efectos de decisiones políticas; los anales son testimonios disponibles para quien quiera reconstruir los hechos, darles vida. La historia se sedimenta en obras y éstas prefiguran generaciones orgullosas o infestadas de venganza. En las obras se buscan las razones para justificar violencias pasadas o intervenciones futuras; en la historia también se condena la injusticia, aunque el juego de razones las ubique tan lejos de la temporalidad que cualquier escozor en el estómago o humedad en los párpados indicaría una pérdida de objetividad del lector. Pero en su búsqueda, la historia que aspira al estatus de ciencia, aunque humana, deja de lado la parte humana de la guerra, en especial, la mirada desconsolada del huérfano, el desespero de la nueva viuda, la impotencia del agredido ante la injusticia, el eclipse de todo lo razonable. Pareciera que, en tanto lejanos a cualquier crónica, estos sufrimientos se tornarían inútiles.

Los escritos del filósofo Emmanuel Lévinas reflejan la tensión de toda filosofía que escape al mero análisis lógico, de toda filosofía que comprenda que la riqueza del lenguaje también implica su desgracia; aunque problemático, el filósofo no se resigna al silencio, no cede su voz a lo absurdo, no renuncia a su rol profético. La tensión que encierran las palabras de Lévinas es incrementada por su condición de periférico, de perseguido; no es extraño, por tanto, que sus obsesiones lo lleven a desconfiar de todo atisbo de totalidad y, para ello, jamás pierde de vista la infinitud del Otro, no categoría abstracta o concepto hueco, sino Rostro que ríe y saluda, rostro que sufre y me exige respuesta, rostro que me seduce y cautiva. Para Lévinas, todo rostro me interpela, rompe mi encapsulamiento (mónada); sin embargo, de entre todos, el rostro del débil es quien arroba con prelación mi conciencia y la desborda.

En tiempos de guerra, tiempos que matizan una generación temerosa de la aniquilación definitiva, la palabra de Lévinas puede servir como faro a la hora de asumir el de otro modo de ser. El presente texto no es más que una aproximación a esta alternativa, alternativa para tiempos de conflicto, donde cada vez son más los que sufren y son escondidos por los hacedores de justicia o los relatores de la historia. Para tal reflexión se tendrá como trasfondo el artículo "El sufrimiento inútil" (1993). El objetivo será mostrar cómo el paso del sufrimiento inútil al sufrimiento no-inútil (Amor) involucra unos desafíos epistemológicos, una crítica a la noción de justicia y un 


\section{Juan Carlos Aguirre}

compromiso por el Otro en perspectiva interhumana. Obviamente, esta exposición tendrá siempre en mente no sólo el holocausto del pueblo judío, sino nuestros coterráneos del Naya y Bojayá, ${ }^{1}$ independientemente de quienes resulten culpables, si alguna vez alguno se personifica.

\section{EL SUFRIMIENTO QUE DESBORDA LA CONCIENCIA INTENCIONAL}

Una de las más importantes intuiciones filosóficas de Husserl la constituye, sin lugar a dudas, su formulación de la intencionalidad. En su versión más simple podría afirmarse que la intencionalidad husserliana reunifica aquello que por siglos estuvo dislocado, a saber: la relación sujeto-objeto. Para Husserl, toda conciencia es "conciencia de" (sentido brentaniano de intencionalidad); sin embargo, todo objeto es, además, "objeto de" una conciencia. No existirían, por tanto, objetos que no se dejaran alcanzar por la mirada iluminadora de la conciencia, como tampoco habría una conciencia vacía que se extasiara contemplándose a sí misma. Sin profundizar sobre la forma como Husserl abordaría la cuestión del sufrimiento, su método en tanto investigación de esencias nos permitiría descubrir lo esencial de ese fenómeno humano, esencia que se aloja y descubre en la nitidez de la conciencia. Bien es sabida la simpatía de Lévinas por Husserl, especialmente después de 1933; sin embargo, también se sabe cuánta admiración incómoda le produjo la tesis de la conciencia intencional ${ }^{2}$ que Lévinas cuestiona en su breve artículo "La conciencia no intencional" (1993), aunque en muchos otros trabajos reitera esta crítica (por ejemplo: La obra de Edmund Husserl (1940); La filosofía y el despertar (1976); Hermenéutica y más allá (1977); Del uno al otro. Trascendencia y tiempo (1983), etc.).

La formulación que hace Lévinas del concepto de intencionalidad es simple: "lo pensado —objeto, tema, sentido- remite al pensamiento que lo piensa, pero determina también la articulación subjetiva de su aparecer: el ser determina sus fenómenos" (1993a:151). No interesa replicar aquí la lectura que Lévinas hace de Husserl ${ }^{3}$ basta llamar la atención en que, tácitamente, se ve

\footnotetext{
${ }^{1}$ En Colombia estos nombres están asociados a las mayores atrocidades cometidas por los grupos armados. Naya remite a dos incursiones de grupos llamados de Autodefensa a territorios indígenas y afrocolombianos, causando la muerte de 300 personas y desplazamiento de otras 6.000 personas. Por su parte, Bojayá recuerda el terror causado por una incursión guerrillera a ese municipio, dejando alrededor de 119 personas muertas en la iglesia del pueblo cuando intentaban refugiarse de los enfrentamientos.

${ }^{2}$ Pese a las críticas que este concepto le genera, Lévinas reconoce su deuda con Husserl: "En el origen de mis escritos está, sin duda, Husserl. A él le debo el concepto de intencionalidad que anima la conciencia y, sobre todo, la idea de los horizontes de sentido que se difuminan cuando el pensamiento es absorbido por lo pensado que tiene siempre la significación del ser" (1993a:151).

${ }^{3}$ Una crítica muy sólida a la interpretación hecha por Lévinas de la obra husserliana la constituye la esquemática reseña que hace Dorion Cairns (2007) (leída y enmendada por el
} 
en la definición un reclamo: en tanto "el ser determina sus fenómenos", Lévinas endilga a Husserl la herencia del intelectualismo y el privilegio del sentido ontológico del ser. Obviamente, para el filósofo obsesionado por el encuentro con el Otro, la intencionalidad husserliana no es sino la justificación de la violencia con la que el Yo vulnera al Otro reduciéndolo al Mismo.

La crítica básica que enuncia Lévinas en el artículo citado descansa en el concepto de experiencia. Tradicionalmente se considera que el sentido de todo se halla en el psiquismo; todo lo que llega al psiquismo se puede saber. Cualquier vivencia se torna experiencia de una psique y, por tanto, es susceptible de saber: "No importa cuáles son sus dimensiones o sus modalidades: contemplación, voluntad o afectividad; sensibilidad o entendimiento; percepción externa, conciencia de sí o reflexión sobre sí; tematización objetivadora o familiaridad de lo no propuesto; cualidades primarias o secundarias, sensaciones kinestésicas o cenestésicas" (Lévinas, 1993a:152). Todo lo que se experiencia es pensable por el pensamiento e, ipso facto, el ser se identifica con lo pensable.

Pese al aparente dominio de la conciencia, Lévinas reivindica tres momentos en los que la experiencia de la conciencia intencional fracasa: a) La intimidad que escapa a la conciencia; b) la conciencia prerreflexiva, no intencional, conciencia desnuda; y, c) la conciencia no intencional como responsabilidad ante el rostro del otro. Las caracterizaciones que hace de cada momento permiten abordar situaciones humanas desde una perspectiva no encerrada en la intencionalidad. Una de ellas es, de modo privilegiado, la cuestión del sufrimiento.

Lévinas parte de la consideración de que el sufrimiento no es ajeno a la conciencia; ingenuo fuera pretender que algo que es nombrado no tuviera una representación. Sin embargo, es claro en sostener que, aunque "contenido psicológico" (como color, sonido, tacto u otra sensación) y pese-a-la-conciencia, se manifiesta como lo inasumible

Es como si, respecto al "yo pienso" kantiano capaz de reunir ordenadamente y de abarcar bajo sus formas "a priori" los datos más heterogéneos y dispersos, el sufrimiento no fuese únicamente un dato refractario a la síntesis sino la forma misma en la que tal rechazo se resiste a la unificación de los datos en un conjunto dotado de sentido: lo que perturba el orden y, al mismo tiempo, la perturbación en cuanto tal (1993b:115).

propio Husserl) al texto primerizo de Lévinas: Théorie de l'intuition dans la phénoménologie de Husserl, cuando quería presentarse en Inglaterra como una introducción a la fenomenología. Otra crítica, más contemporánea, se encuentra en Nam-In Lee (2007), quien cuestiona la lectura que hace Lévinas al concepto de evidencia en Husserl. En ambas críticas, Lévinas es visto como un intérprete errado de Husserl. Una reconstrucción de las críticas puede encontrarse en Aguirre (2009). 


\section{Juan Carlos Aguirre}

Lo que propone Lévinas es una revisión de la conciencia que tradicionalmente se asume como "aprehensión" para darle un estatus revulsivo: el sufrimiento, en tanto insoportable, escapa a toda posibilidad de soporte comprensivo, adoptando la forma del "no-soportar-se". En este caso, el sufrimiento sentido, siendo dato sin quedarse en dato, ${ }^{4}$ no se aloja en la conciencia activa, como si pudiera tomarse conciencia de él; es pasividad en la medida en que se padece la adversidad. Hay que aclarar que pasividad, aquí, no es el reverso de actividad; no es la pasividad tipo tabula rasa que pregonaba el empirismo. El sufrimiento como pasividad supera la mera receptividad, pues "en el sufrimiento, la sensibilidad es vulnerabilidad, es más pasiva que la receptividad; es una prueba, y es más pasiva que la experiencia" (1993b:116).

Para ilustrar la radicalidad del sufrimiento que escapa a la conciencia intencional, Lévinas plantea que éste no sería un desafío a la libertad humana: "La humanidad del hombre que sufre se halla abrumada por el mal que la desgarra, pero de un modo distinto a como le abruma la no-libertad; de un modo violento y cruel, de forma más irremisible que la negación que domina o paraliza el acto en la situación de no-libertad" (1993b:116). El sufrimiento, según esta consideración, se anclaría sólo en el sin-sentido, en el absurdo.

Lévinas, para ejemplificar su planteamiento, recurre al sufrimiento en situaciones clínicas. Sin embargo, el sufrimiento puede experimentarse en casos históricamente conocidos como el de Job o en los sucesos tristemente cotidianos como el de la esposa cuyo hombre es despedazado frente a ella sin otra posibilidad que la del grito. En ninguno de estos casos hay razones, ninguna conciencia puede justificar o soportar el rigor del mal; no obstante, el sufrimiento que evidencia lo absurdo excede todo control y se desborda suplicando auxilio

¿No es al mismo tiempo lo inasumible y, merced a su no integración en un orden y en un sentido, la posibilidad de una curación y, más exactamente, aquella en la que tiene lugar un ruego, un grito, un gemido o un suspiro, demanda de ayuda originaria; petición de un auxilio curativo, un auxilio de otro yo cuya alteridad, cuya exterioridad promete la salvación? (1993b:117).

El gemido del enfermo, la lamentación de Job, el grito desgarrado de la viuda no se lanzan al vacío de la indiferencia. Reclaman y exigen respuesta y es esta respuesta la que otorga algún sentido al sin-sentido del sufrimiento del Otro. El gemido, la lamentación, el grito desgarrado, es decir, el sufrimiento del Otro es un

\footnotetext{
${ }^{4}$ Lévinas plantea esta situación como una cuasi-contradicción. Sin embargo, agrega: "una contradicción que no es formal como la que se produce en el intelecto entre lo afirmativo y lo negativo; contradicción en forma de sensación: dolencia del dolor, mal" (1993b:115-116).
} 
requerimiento a lo nuclear de la subjetividad humana. Podría afirmarse que se es típicamente humano sólo cuando el sufrimiento se convierte en "sufrimiento por el sufrimiento -incluso inexorable - de otro" (1993b:119). Es este el principio ético supremo (Lévinas dice: "el único incontestable") el que debe "gobernar las esperanzas y el disciplinamiento práctico de grandes agrupaciones humanas" (1993b:117).

\section{LA JUSTICIA QUE BROTA DE LA VERDAD O EL SUFRIMIENTO QUE NO ADMITE RAZONES}

El apartado anterior ha concluido con la enunciación del principio ético supremo. Pueden considerarse, ahora, los caminos que este principio, familiar al discurso político, ha intentado recorrer. Es necesario advertir que pretender operativizar tal imperativo bajo el juego de las razones puede favorecer la sedimentación de estructuras de conciencia en las que el sufrimiento pierde su sentido (se torna inútil), reduciéndose a mero dato susceptible de mitigar, curar o reparar. Para justificar esto, se planteará inicialmente la tensión que surge entre justicia y verdad; posteriormente, se analizará la relación privilegiando la verdad sobre la justicia bajo dos casos: a) los Derechos Humanos, y b) el sufrimiento englobable en la teodicea. Finalmente, se invertirá la relación y se concluirá el apartado sosteniendo que el sufrimiento no admite razones.

Como es de suponer, la filosofía de Lévinas, que se caracteriza por reivindicar la no intencionalidad de la conciencia, no buscará la verdad como un fin en sí mismo; al menos no como mera adecuación de la mente con las cosas. La verdad es identificada por Lévinas con la autonomía y la plenitud del ser; por ser autonomía, remite a la separación y al gozo (egoísmo del yo que ignora al otro). Lévinas no está otorgando un cariz negativo a esta actitud, como si se tratara de una tesis a la que hay que oponer dialécticamente la antítesis, con miras a superarla. Para él, la separación es una exigencia: "la separación atea es exigida por la idea de lo Infinito" (1977:84) y no se supera en el encuentro con el Otro, ella permanece en la relación Mismo-Otro.

Pero esta verdad no es la seguridad para el bien. Ni siquiera para el actuar correcto. Más aún, en la interioridad del yo, de donde brota toda verdad, se da también la "eventualidad de todos los crímenes impunes" (1977:84). Para ilustrarlo Lévinas recurre al Mito de Giges narrado por Platón: un pastor que estaba al servicio del entonces rey de Lidia, habiendo soportado un terremoto, vio en el fondo de una grieta — entre otras cosas - un cadáver que no llevaba sobre sí más que una sortija de oro en la mano. El pastor se la quitó y se fue. Ya en el pueblo, el pastor descubrió que el anillo tenía el poder de volverlo invisible o visible en el momento cuando lo deseara. "En cuanto se hubo cerciorado de ello, maquinó el modo de formar parte de los que fueron a la residencia del rey como informantes; y una vez allí sedujo a la reina, y con ayuda de ella mató al rey y se apoderó del 
gobierno" (Platón, 1992:108). La argumentación culmina con la conclusión de que nadie es justo de grado sino por coerción.

No es fortuito que en el relato de Platón aparezcan expresiones que remitan a la conciencia intencional, conciencia caracterizable en términos de Luz: ${ }^{5}$ asombrado al ver esto..., descendió al abismo y halló..., divisó adentro..., se asombró..., al advertirlo..., comprobó..., etc. La verdad conocida, en este caso, le sirvió a Giges para reducir todo a la medida de su visión, para satisfacer su gozo y ser feliz. Ninguna razón convencería a Giges de su despropósito. Ningún remordimiento le llevaría a examinar las palabras que usó para seducir a la esposa del rey. Ningún contrincante lo derrocaría de su reino, pues el poder que ha adquirido le da los argumentos para persuadir.

Se puede reiterar que la verdad no conlleva bondad, que las razones $a$ priori que justifican una acción no exigen el ideal de justicia. Para que esto se dé, es preciso que nazca el deseo que brota, no de mi voluntad, sino de la revelación del Otro: del Otro del que yo me separo de modo ateo para asegurar mi intimidad. Sin embargo, en la epifanía del Otro (l'Autrui), éste se revela como Infinito. Ahora bien, lo infinito no es "objeto" de un conocimiento - lo que lo reduciría a la medida de la mirada que contemplasino lo deseable, lo que suscita el Deseo, es decir, lo que es abordable por un pensamiento que en todo momento piensa más de lo que piensa (1977:85). En este punto, Lévinas establece una diferencia radical entre gozo y deseo; y en este último ubica la justicia como Deseo absolutamente no egoísta. De igual modo, en el gozo o felicidad se apuntala la política, mientras que en el deseo se afinca la religión.

Otro elemento que entra en juego en esta tensión entre verdad y justicia lo constituye el discurso. Pese a su injusticia, Giges puede reinar a través de la retórica (limitándonos, al menos, sólo a la literalidad del relato platónico, su discurso permitió acudir a la retórica para seducir a la esposa del rey y así allanar el camino al poder). Retórica e injusticia se identifican, en tanto la primera corrompe la libertad a través de la propaganda, la adulación o la diplomacia. La justicia exige un discurso que no encubra la verdad que sólo pretende el asentimiento; al contrario: "si la verdad surge en la experiencia absoluta en la que el ser brilla por su propia luz, la verdad sólo se produce en el verdadero discurso o en la justicia" (1977:94).

\footnotetext{
${ }^{5}$ Para Lévinas, un objeto iluminado es algo que encontramos; pero, por el mismo hecho de estar iluminado, es como si de nosotros saliese la luz. La crítica que a este respecto se lanza es que, aunque se aspira a una trascendencia, a una exterioridad, ésta queda envuelta en la inmanencia. Con fino convencimiento, Lévinas sostiene que "el mundo y la luz son la soledad. Estos objetos dados, estos seres vestidos, son otra cosa que yo mismo, pero son míos. Iluminados por la luz, tienen un sentido y, por consiguiente, son como si vinieran de mí" (2000:115).
} 
Al comienzo de este apartado se había hecho mención del principio ético supremo, el único incontestable. Luego de haber establecido algunos presupuestos que acompañan este principio, se pueden plantear dos actitudes a la hora de contestar a ese principio. La primera forma es privilegiando la verdad como fundamento que asegura la justicia; se tiene, entonces, que el actuar justo está precedido por un conocimiento de causa y esto es lo que permite dar razones de nuestros actos. En esta lógica, nadie que conozca puede infligir actos injustos; la injusticia brota de la ignorancia o de la desviación del juicio recto. Esta alternativa puede presentarse como establecimiento de principios a priori o como posibilidad de encontrar sentido mediante el padecimiento de algo, a sabiendas que al final todo se aclarará, como ocurriría en los casos de los Derechos Humanos y del sufrimiento.

En Altérité et transcendance (2006), Lévinas hace una breve alusión a los Derechos del Hombre. Allí plantea que "la característica formal de los Derechos del hombre - tal como son pensados desde el Renacimientoconsiste en que están vinculados con toda persona humana independientemente de toda concesión previa venida de alguna autoridad o tradición” (2006:149). En los Derechos del Hombre se destaca su carácter de igualdad ("no importando cuáles sean las diferencias físicas o mentales, personales o sociales que distinguen a los hombres entre sî") y su carácter a priori ("anteriores a toda ley convenida"). La efectividad que los Derechos del Hombre poseen, su poder de vinculación y su influjo en lo jurídico están ligados a unas condiciones sociales y psicológicas que, a decir de Lévinas, "deben mucho al estado cultural, técnico y económico de una sociedad, a sus estructuras y revoluciones, a la influencia de las civilizaciones extranjeras, vecinas y lejanas, a la lucidez y a la agudeza intelectual de sus ciudadanos" (2006:150). Estas condiciones no son, en modo alguno, el fundamento de los derechos; sin embargo, no desvirtúan su carácter de a priori en la persona humana.

Vistos así, los Derechos del Hombre conservan una especie de dignidad humana y, en esa medida, son derechos que salvaguardan la libre voluntad; esta libre voluntad no se dispersa en consideraciones abstractas, sino que remite a la concreción del orden empírico del hombre: su vida, el trabajo, las vacaciones, la seguridad social. Para que estos derechos se consoliden van estudiándose, a partir de las ciencias humanas positivas ("atentas, sobre todo, a las leyes de la causalidad") las mecánicas de la realidad social, de modo que los defensores de los Derechos del Hombre se tornan técnicos cuya tarea fundamental no es sólo despertar la conciencia de los pueblos subdesarrollados o tiranizados, sino también reformistas que, ante un obstáculo, podrían accionar el estilo de la lucha de clases.

Alcanzado este punto se llega a este dilema ¿En aras de la instauración de los Derechos del hombre, puede justificarse la guerra de todos contra todos, o, 
para evitar la guerra, puede apelarse a la solución razonada del conflicto? La respuesta kantiana es conocida por Lévinas para quien, "la multiplicidad de voluntades libres se reconcilia en el "Reino de los fines". La paz entre libertades es posible gracias a la noción de 'buena voluntad' que será razón práctica, voluntad que escucha y entiende a la razón" (2006:152). Ésta sería la respuesta a los casos de injusticia, éste su modo de comprender o reorientar las acciones de Giges. Obviamente, Lévinas no coincide con este modo de hallar la justicia previamente al encuentro de la verdad. Más que a la buena voluntad recurrirá a la bondad; por lo tanto, en vez de analizar este concepto, es preciso considerar el caso del sufrimiento donde, pese a no invocar lo a priori sino el telos, se reafirma la misma conclusión.

Del sufrimiento se ha dicho que desborda toda contención de la conciencia intencional. Sin embargo, continuando con el análisis que plantea la dependencia de la justicia a la verdad, podría intentarse ver el sentido del sufrimiento apelando a una razón explicativa: "Ya en el interior de una conciencia aislada, el dolor de sufrir puede adquirir el sentido de una pena que merece y espera un salario, y parece perder así de diversos modos su modalidad de inútil" (1993:119). En el plano individual, el sufrimiento templaría el carácter o, al menos, serviría como indicador fisiológico, un síntoma que alerta de los peligros de una enfermedad. En el plano social, el sufrimiento de una comunidad permite llamados de atención que deben suplirse en pro del bienestar del cuerpo colectivo; en este caso, la utilidad del sufrimiento sería recogida por el Poder para que, de modo pedagógico, emprendiera acciones de formación, dirección y represión. Asumiendo razones personales o sociales, el sufrimiento adquiere un sentido: "Es esta, en verdad, una teleología política fundada en el valor de la existencia, en la perseverancia de la sociedad y del individuo en el ser, en su bienestar admitido como fin último y supremo" (1993:119-120).

La búsqueda del sentido del sin-sentido del sufrimiento es nominada por Lévinas como Teodicea". En tal caso, el sufrimiento se torna "un dolor que, por tanto, tiene sentido; que está subordinado de una u otra forma a la finalidad metafísica adivinada por la fe o por la creencia en el progreso...

\footnotetext{
${ }^{6}$ El término Teodicea no es una formulación exclusiva de Lévinas. En la tradición filosófica se entiende la Teodicea como una explicación justificada de por qué Dios permite el mal, una respuesta al problema del mal. Quien estudia la Teodicea formula que es necesario tomar los propósitos racionales y reales, que explican y justifican las acciones e inacciones divinas con respecto al mal. Sin embargo, Lévinas hace una reformulación del término, no circunscribiéndolo únicamente a la presencia de un Dios. Según Lévinas, bien podría ser Dios cuya sabiduría providente permitiría el sufrimiento del hombre en aras de su purificación; pero también podría ser "una bondad invisible, expandida por la Naturaleza y por la Historia y que gobierna sus caminos, sin duda dolorosos pero conducentes al bien" (1993b:120).
} 
¡Creencias todas ellas presupuestas por la teodicea! Esta es la gran idea necesaria para la paz interior de las almas en nuestro aquejado mundo. La invocamos para hacer comprensibles los sufrimientos de este mundo" (1993:120).

El sentido, en este caso, fundaría un orden justo que comprende y tolera el sufrimiento merced a su función depuradora para lograr el Bien - principio presente, por ejemplo, en el coro del Himno Nacional de la República de Colombia, "En surcos de dolores, el bien germina ya"-siempre y cuando los Derechos del hombre aún se preserven; es decir, hasta el sufrimiento queda regulado y adquiere un estatus dentro del orden establecido.

En los dos casos considerados, Lévinas plantea las dificultades de una justicia anclada en la verdad o de un sufrimiento razonado y razonable. En el primer caso, apoyado en su dimensión política, el Derecho tiende a la felicidad de todos por igual; así pues, la ley política acaba y consagra la lucha por el reconocimiento; sin embargo, en tal lucha no tiene su génesis la conciencia de indignidad moral. Reconocer, racionalmente, los hechos no implica la vergüenza del culpable; más aún, sus elucubraciones enunciativas continúan dándole la razón. Lévinas lo plantea de este modo: la verdad no se deduce de la verdad; la conciencia primera de mi inmoralidad no es una verdad a la que llego después de un proceso de concientización; la indignidad moral precede a la verdad. De modo contundente sostiene: "La conciencia de indignidad no es, a su vez, una verdad, no es una consideración del hecho. La conciencia primera de mi inmoralidad no es mi subordinación al hecho, sino al Otro, a lo Infinito (...) La libertad que puede tener vergüenza de sí misma funda la verdad" (1997:106).

Sin brotar de la verdad, la justicia transforma también las prácticas discursivas. La palabra no se lanza a un interlocutor anónimo, a un testigo mudo de mi confesión. La palabra que lanza el culpable promete respuesta a aquel que está en posibilidad de preguntar; pero es superación del juego dialéctico, pues la verdad no es el objetivo, el convencer no es la meta. El nuevo contexto en el que la palabra significa exige una asociación entre quien enuncia y el oyente; por lo pronto, esta asociación supera el plano de las capacidades cognoscitivas que asegurarían la comprensión; también supera las pretensiones de igualdad de los interlocutores. La asociación sólo se reconoce como moral, "de suerte que la verdad se funda en mi relación con el Otro o la justicia. Poner la palabra en el origen de la verdad es abandonar el develamiento que supone la soledad de la visión, como obra primera de la verdad" (1977:122). Igualmente exige la asimetría, pues "el lenguaje sólo puede hablarse, en efecto, si el interlocutor es el comienzo de su discurso, si permanece en consecuencia, más allá del sistema, si no está en el mismo plano que yo. El interlocutor no es un Tú, es un Usted. Se revela en su señorío" (1997:124). De ahí que se necesite una reevaluación de los Derechos del hombre anclados en la igualdad; pues su aplicación fracasaría, 


\section{Juan Carlos Aguirre}

"excepto si fue concedida una primacía al otro por bondad; excepto si la buena voluntad era querida, no solamente por respeto a la universalidad de una máxima de acción, sino por el sentimiento de bondad" (2006:152).

Respecto al sufrimiento, Lévinas también denuncia que ha superado todo molde en el que la teodicea intentaba encuadrarlo. Menciona Hiroshima, Auschwitz, Camboya; nosotros agregaríamos muchos más nombres bárbaros que siguen asumiéndose como datos en el juego político (de una política que obviamente se ha desprendido de toda ética). Ya no hay posibilidad moral de explicar el sufrimiento en Auschwitz a partir de alguna fe milenaria. No hay posibilidad de incoar sentido a las madres, o hijos, o hermanos, o esposas sobrevivientes del Naya o Bojayá, pues "la justificación del dolor del prójimo es ciertamente el origen de toda inmoralidad" (1993b:123).

Cabe preguntarse, entonces, ante el mal radical, ante el fracaso de toda religiosidad como moralidad humana de bondad, si los sufrimientos se entregarán a la totalidad política, a las "fuerzas ciegas que infligen la desgracia a los débiles y a los vencidos y se la ahorran a unos vencedores aliados con los malvados" (1993:124); en última instancia, si nuestro sufrimiento, juzgado a partir de la verdad, continuará siendo inútil o, invirtiendo los términos de la relación, si podrá adquirir el sentido de no-inútil. La apuesta de Lévinas es por esto última y, para ello, propone la contemplación del sufrimiento en perspectiva interhumana.

\section{EL ROSTRO DEL QUE SUFRE: PENSAR EN OTRO}

Podría decirse que toda la obra de Lévinas nace y tiende hacia la consideración de los fenómenos en perspectiva interhumana, ${ }^{7}$ con lo cual, Lévinas quiere indicar algo distinto a una mera coexistencia de una multiplicidad de conciencias; algo diferente a las apelaciones al determinismo social o de un saber que afirmaría la proximidad en un lugar o el establecimiento de un destino común. Todas estas situaciones pueden alentar el orden político de la ciudad, pueden ser reguladas por la Ley. Sin embargo, cuando Lévinas habla de perspectiva interhumana, habla de la no-indiferencia de los unos por los otros, no-indiferencia que no está considerada en la simple reciprocidad que brota de un código. Un orden interhumano que no puede homologarse a orden político, pues, el factor

\footnotetext{
${ }^{7}$ A diferencia de otros autores, en Lévinas es fácil advertir su obsesión, la cual consiste —en palabras de Critchley - en que "la ética es la filosofía primera, entendiendo por ética una relación de responsabilidad infinita hacia la otra persona" (2004:6). Putnam retoma la metáfora de Isaah Berlin según la cual los pensadores pueden dividirse en "erizos" (quienes saben "una gran cosa") y zorros (quienes saben "muchas cosas pequeñas") (...) Necesitamos muchos erizos. Pero, ciertamente, uno de los erizos que necesitamos escuchar es Emmanuel Lévinas" (2004:58).
} 
post-ético o pre-ético que inaugura el "contrato social" no es ni condición insuficiente ni cumplimiento necesario de la ética. En su posición ética, el yo es distinto del ciudadano aislado que emana de la Ciudad tanto como el individuo cuyo egoísmo natural precede a todo orden pero del que la filosofía política intenta - o consigue - desde Hobbes, extraer el orden social o político de la ciudad" (1993b:125).

Como puede verse, no basta el correcto cumplimiento de los Derechos, ni siquiera de los del hombre, para superar el carácter inútil de los sufrimientos del Otro. El principio supremo se aloja en la ética, pero ésta tiene que trascender el estatus de "simple intercambio de buenos modales establecido como "comercio interpersonal" en el seno de las costumbres" (1993b:125); es decir, el yo y el otro que responden al principio ético supremo son figuras distintas de las que brotan del estado de Naturaleza o del estado civil. La transformación del sufrimiento inútil en sufrimiento no-inútil, es decir, en Amor, involucra "mi responsabilidad respecto del otro hombre, sin esperanza de reciprocidad, de exigencia gratuita de auxiliarle, de la asimetría de la relación entre el uno y el otro" (1993b:126). En definitiva, involucra la instauración del orden interhumano auténtico.

Para concluir, retomemos una frase que quedó suelta anteriormente: en el gozo o felicidad se apuntala la política, mientras que en el deseo se afinca la religión. La religión, que para Lévinas supera lo oficial encuadrado en la Teodicea, permite comprender la exigencia del principio ético supremo. Baste para ilustrar estas reflexiones, el siguiente caso desgarrador que se halla al final de Cuatro lecturas Talmúdicas, un hermoso texto de Lévinas dedicado al perdón desde una perspectiva judía

Y lo que queda también, tras esta sombría visión de la condición humana y de la misma Justicia, lo que se eleva por encima de la crueldad inherente al orden racional (y quizá, sencillamente, al Orden), es la imagen de esa mujer, de esa madre, de esta Ritspá bat Ayyá que por seis meses monta guardia junto a los cadáveres de sus hijos, mezclados con los cadáveres de quienes no son sus hijos, para preservar de los pájaros del cielo y de las bestias de los campos a las víctimas de la implacable justicia de los hombres y de Dios. Lo que queda después de tanta sangre y de las lágrimas vertidas en nombre de principios inmortales, es la abnegación individual, que, entre los saltos dialécticos de la justicia y todos sus contradictorios virajes, encuentra sin vacilar un camino derecho y seguro (1996:52-53).

Universidad del Cauca*
Departamento de Filosofía
Claustro El Carmen, Calle 4 \# 3-56. Popayán-Cauca (Colombia)
jcaguirre@ @unicauca.edu.co


Juan Carlos Aguirre

\section{BIBLIOGRAFÍA}

AGUIRRE, Juan. "El no seguir el camino o las rutas abiertas del hereje", en Anuario Colombiano de Fenomenología, volumen III (2009):133-145.

CAIRNS, Dorion. Review of Emmanuel Lévinas, Théorie de l'intuition dans la phénoménologie de Husserl. Paris: Librairie Philosophique J. Vrin, 1930. Traducción del alemán por Fred Kersten (2007). Versión electrónica en: http://www.dorioncairns.net/Lévinasreview.htm

CRITCHLEY, Simon. "Introducción", en Critchely, Simon y Bernasconi, Robert (Eds.). The Cambridge Companion to Lévinas. Cambridge: Cambridge University Press, 2004:1-32.

LEE, NAM-IN. "Experience and Evidence", en Husserl Studies 23/3 (2007):229-246.

LÉVINAS, Emmanuel. Altérité et transcendance. Paris: Le livre de Poche, 2006.

----- De la existencia al existente. Madrid: Arena libros, 2000.

------ Cuatro lecturas talmúdicas. Barcelona: Riopiedras Ediciones, 1996.

------ "La conciencia no intencional", en Entre nosotros; ensayos para pensar en otro. Valencia: Pre-textos, 1993:149-160.

------ "El sufrimiento inútil", en Entre nosotros; ensayos para pensar en otro. Valencia: Pre-textos, 1993:113-126.

- Totalidad e infinito; ensayo sobre la exterioridad. Salamanca: Sígueme, 1977.

PLATÓN. "República", en Diálogos IV. Madrid: Gredos, 1992.

PUTNAM, Hilary. "Lévinas and Judaism", en The Cambridge Companion to Lévinas. Cambridge: Cambridge University Press, 2004:33-62. 